\title{
PERCEPÇÃO DOS CIDADÃOS DO MUNICÍPIO DO RIO DE JANEIRO QUANTO À RESPONSABILIDADE PELA SITUAÇÃO HÍDRICA ATUAL
}

\author{
Daniel Shimada Brotto ${ }^{1}$ \\ Giuliana Tavares Dias ${ }^{2}$ \\ Jessika Santana Pereira ${ }^{3}$ \\ Vera Lucia Vaz Agarez 4
}

Resumo: Os problemas de escassez hídrica no Brasil decorrem, fundamentalmente, da combinação do crescimento exagerado das demandas localizadas e da degradação da qualidade das águas. Esse quadro é consequência do aumento desordenado dos processos de urbanização, industrialização e expansão agrícola, verificado a partir da década de 1950 . O objetivo do presente trabalho foi avaliar a percepção dos moradores do Município do Rio de Janeiro com relação à situação atual dos recursos hídricos, além de conhecer e avaliar as influências do perfil socioeconômico nessa questão. Para isso, foram aplicados questionários a 300 moradores de seis determinados bairros do Município do Rio de Janeiro. Concluindo que o perfil dos respondentes influencia na sua percepção e que o desenvolvimento social deve ser seriamente considerado.

Palavras-chave: Recursos Hídricos; Crise Hídrica; Educação; Desenvolvimento Social.

1 Universidade Veiga de Almeida, Rio de Janeiro, RJ. E-mail: danshima@ig.com.br

2 Universidade Veiga de Almeida, Rio de Janeiro, RJ. E-mail: giu-tavares@hotmail.com

${ }^{3}$ Universidade Veiga de Almeida, Rio de Janeiro, RJ. E-mail: jssikasantana@yahoo.com.br

4 Universidade Veiga de Almeida, Rio de Janeiro, RJ. E-mail: vagarez@hotmail.com 


\section{Introdução}

Segundo Tuan (1980), a percepção é uma resposta dos sentidos aos estímulos externos, como a atividade proposital, na qual certos fenômenos são claramente registrados, enquanto outros são bloqueados. O mesmo afirma que cada grupo social possui valores relativos atribuídos a ele em função das experiências coletivas e individuais, sendo que o meio ambiente tem diferentes significados de acordo com os indivíduos.

Para Villar et al. (2008), a percepção ambiental pode ser definida pelas formas como os indivíduos veem, compreendem e se comunicam com o ambiente, considerando-se as influências ideológicas de cada sociedade. Segundo Maia e Guedes (2011), estudar a percepção e a relação que as populações locais têm com seu entorno, permite compreender seu nível de abstração e comprometimento com questões relacionadas ao meio ambiente. $\mathrm{E}$, a investigação da percepção nas relações ser humano-ambiente contribui para a utilização menos impactante os recursos ambientais, possibilitando o estabelecimento de relações mais harmônicas entre o homem e o meio (FIORI, 2002). Entendendo-se que é imperativa a avaliação de concepções ambientais previamente à proposição de ações de educação ambiental (PEDRINI et al. 2013).

Estiagens prolongadas e chuvas excessivas, podem ser entendidas como situações críticas derivadas das mudanças climáticas e segundo Lima e Layrargues (2014) a intensificação dos eventos climáticos extremos em todo o planeta comprometem a saúde, o bem estar e a economia, não obstante, são poucos os que tomam atitudes concretas quanto a essa situação, devido basicamente à invisibilidade da problemática na vida cotidiana; "lobbies" econômicos que alimentam as controvérsias sobre o tema e da inércia da população e das autoridades instituídas.

É de grande importância saber como a população percebe a situação dos recursos hídricos e como lida com tal situação. Através da percepção ambiental podemos obter esse conhecimento, e, com ele, desenvolver uma melhor gestão dos recursos hídricos e programas de conscientização eficazes e direcionados, para que a população tenha consciência e dê valor a este recurso, visando a sustentabilidade sócio ambiental. O presente trabalho parte do pressuposto de que a atual situação socioambiental é responsabilidade de toda a sociedade, e o foco principal da pesquisa está na percepção ambiental dos moradores do Município do Rio de Janeiro sobre essa responsabilidade e como essa percepção é influenciada pelo seu perfil socioeconômico.

Visto que, mesmo com toda a informação de fácil compreensão disponível quanto aos recursos hídricos, quanto à situação do nosso Planeta, que estão disponibilizadas em diferentes formas e a partir de diversas fontes, existe pouca compreensão e assimilação do assunto. É necessário avaliar-se de forma mais aprofundada tanto as questões como as consequências das intervenções diretas e indiretas nas bacias hidrográficas e outros mananciais, 
assim como o uso consciente da água e a percepção do cidadão sobre os recursos hídricos, temas pouco explorados em trabalhos acadêmicos.

\section{Material e métodos}

Os estudos de percepção ambiental devem visar à análise das causas e implicações das concepções e atitudes identificadas no público amostrado e são subsídios técnicos para as ações de educação ambiental. Assim, no presente estudo foram amostrados os seguintes bairros no município do Rio de janeiro, seguindo a ordem crescente de acordo com o Índice de Desenvolvimento Social (IDS): Realengo, Madureira, Taquara, Santa Teresa, Tijuca e Jardim Botânico (Figura 1).

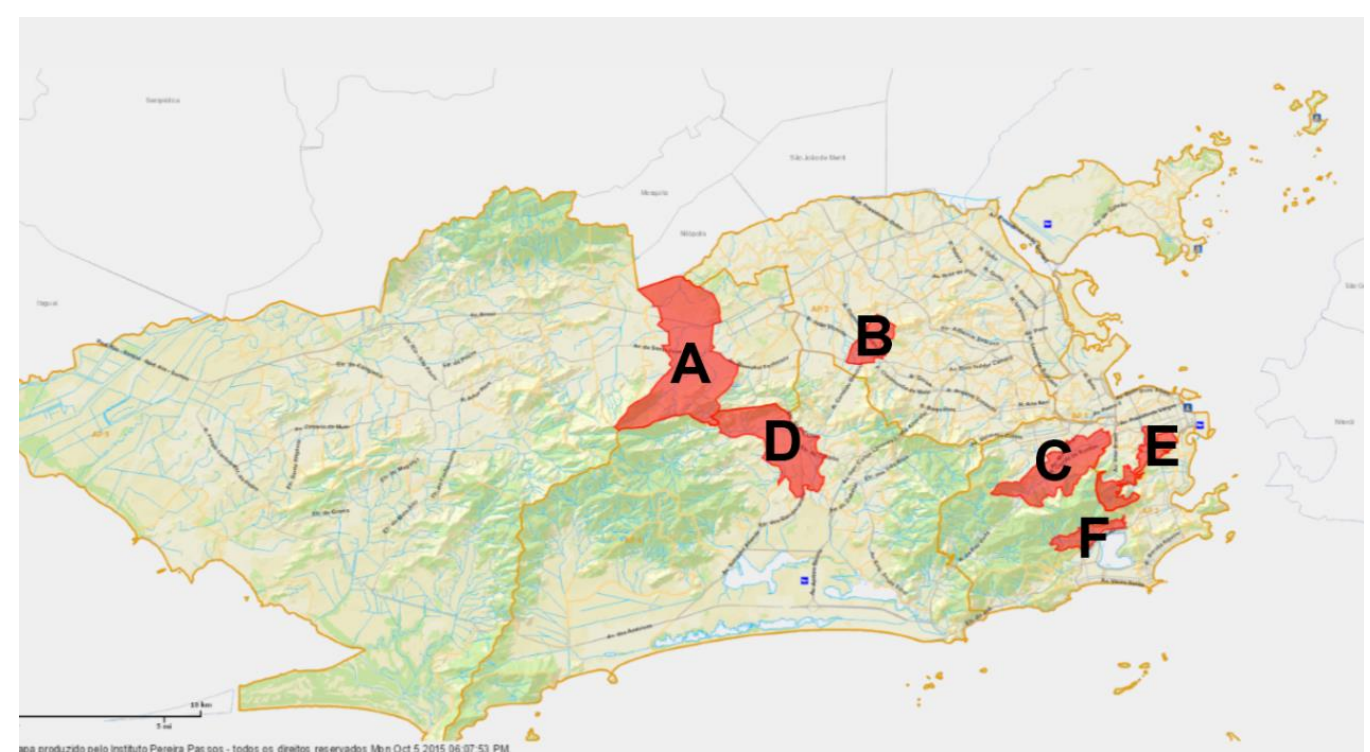

Figura 1: Mapa do município do Rio de Janeiro, com a demarcação dos seis bairros, nos quais foram aplicadas as entrevistas (Realengo (A), Madureira (B), Tijuca (C), Taquara (D), Santa Teresa (E) e Jardim Botânico (F)).

O presente trabalho utilizou-se de uma abordagem qualitativa com o objetivo de conhecer a percepção de moradores dos seis bairros selecionados. Nessa seleção foram considerados bairros representativos do município do Rio de Janeiro, baseado nos padrões socioeconômicos dos seus moradores. $\mathrm{Na}$ amostragem foram entrevistados 300 moradores, sendo 50 moradores por bairro, as entrevistas foram realizadas iniciando pelo turno da manhã e terminando no turno da tarde, deslocando-se pelas ruas de maior fluxo, entre os dias 06 e 16 de Julho de 2015.

A metodologia de Entrevistas foi escolhida por oferecer informações importantes sobre o perfil socioeconômico, que foram utilizadas para avaliar suas influências na percepção, para a entrevista, foi elaborado um questionário objetivo para a coleta de dados referentes ao perfil socioeconômico do 
entrevistado, especificamente: Bairro de moradia, sexo, idade, número de filhos, estado civil, ocupação, tipo de moradia, escolaridade, faixa salarial, frequência de abastecimento e presença de medidor, além de questões objetivas relacionadas à percepção e atitudes frente à situação hídrica atual. $\mathrm{O}$ presente trabalho tem o propósito de avaliar especificamente a percepção dos cidadãos quanto à responsabilidade pela atual situação hídrica, avaliando a influência das variáveis do perfil socioeconômico nessa percepção. Dessa forma, a questão analisada no presente trabalho foi: Quem é responsável pela situação hídrica atual? Onde os entrevistados poderiam responder: governo, população, indústrias, assim como, atribuir a responsabilidade a dois setores específicos ou a todos.

As respostas foram interpretadas e agrupadas em categorias específicas, permitindo a análise quali-quantitativa dos dados por meio de representações gráficas e do teste do quí quadrado, avaliando-se as influências das variáveis do perfil socioeconômico na distribuição de frequências das respostas, e por fim, foram identificadas as variáveis consideradas mais importantes no estabelecimento da percepção da responsabilidade.

\section{Resultados e discussão}

Os bairros com maiores frequências de respondentes que consideram que a responsabilidade pela situação hídrica seja coletiva, foram Tijuca e Madureira, sugerindo maior conscientização da situação hídrica. Por outro lado, em Realengo, a significativa $(X 2=35,4783, G L=5$ e $p<0,05)$ maioria dos entrevistados considera o governo como responsável pela situação atual. Esse fato seria explicado por fatores relacionados ao menor índice de desenvolvimento social em Realengo (IPP, 2008), fazendo supor que a insatisfação com a qualidade de vida seja o motivo de se responsabilizar o governo pela situação atual, isso pode estar associado também ao menor acesso à informação, acarretando uma percepção deficiente sobre as responsabilidade dos cidadãos nas questões ambientais, assim, demonstrando sua dependência por políticas paternalistas e obscurecendo a percepção da responsabilidade das empresas (Figura 2).

As mulheres apresentaram frequência superior de respondentes que consideram a responsabilidade como coletiva, porém, não de forma significativa ( $X 2=5,4912, G L=1$ e $p>0,05)$. De acordo com Baden (1993), de modo geral, numa visão cultural, as mulheres possuem uma melhor compreensão dos recursos hídricos por serem os principais usuários de água em suas atividades domésticas, essa compreensão pode levá-las a uma maior identificação com esta responsabilidade e uma percepção ambiental mais abrangente (Figura 3). 


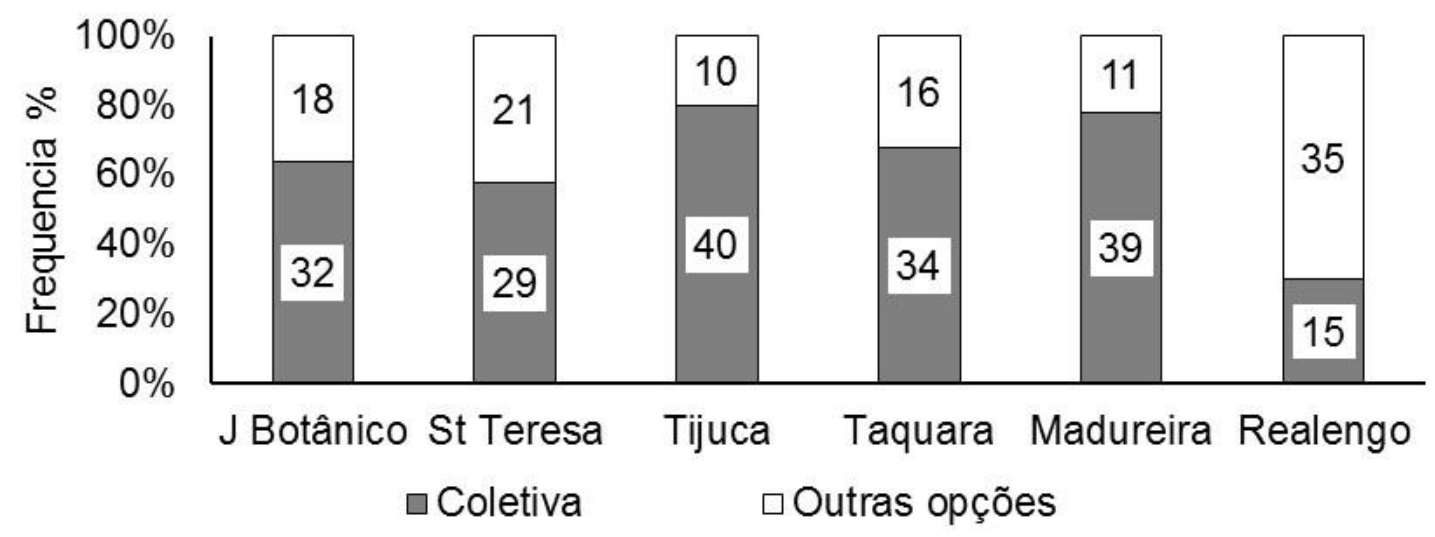

Figura 2: Frequências percentuais para a percepção da responsabilidade pela situação hídrica atual de acordo com o bairro de moradia, os valores apresentados nas barras referen-se às frequências absolutas.

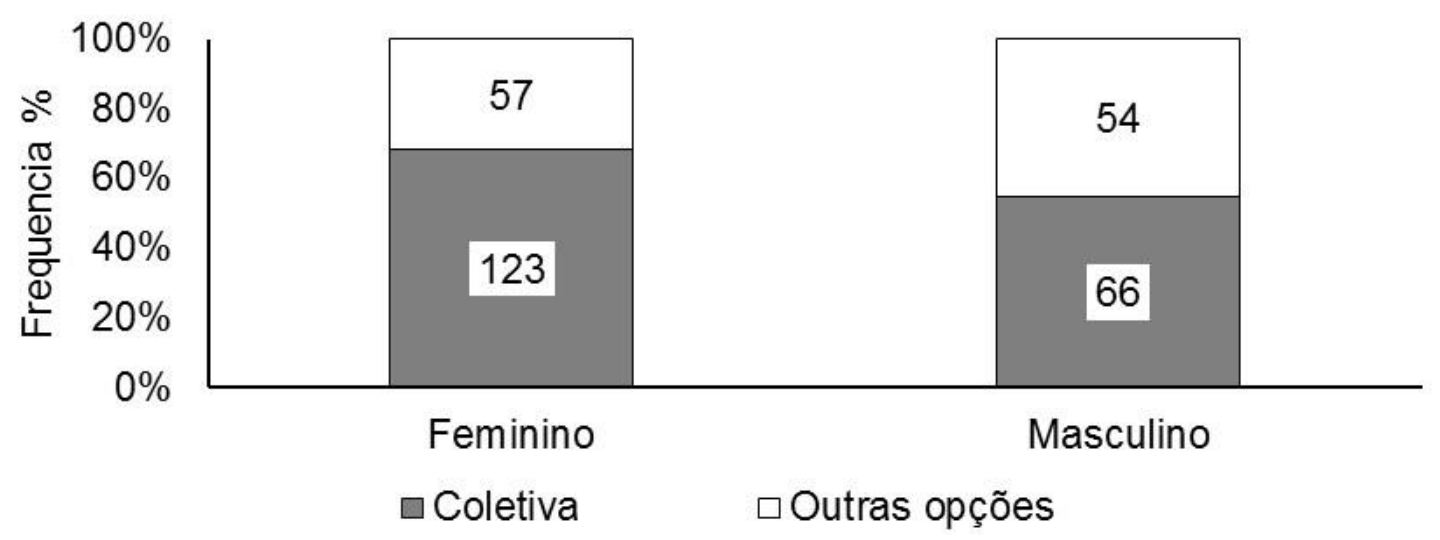

Figura 3: Frequências percentuais para a percepção da responsabilidade pela situação hídrica atual de acordo com o sexo, os valores apresentados nas barras referen-se às frequências absolutas.

A frequência de respondentes que assinalam a opção da responsabilidade coletiva foi significativamente superior $(X 2=6,0529, G L=2$ e $\mathrm{p}<0,05)$ para os respondentes sem filhos, sugere-se esse fato se deva à intromissão de outros fatores socioeconômicos como idade, escolaridade, profissão e poder aquisitivo (Figura 4). 


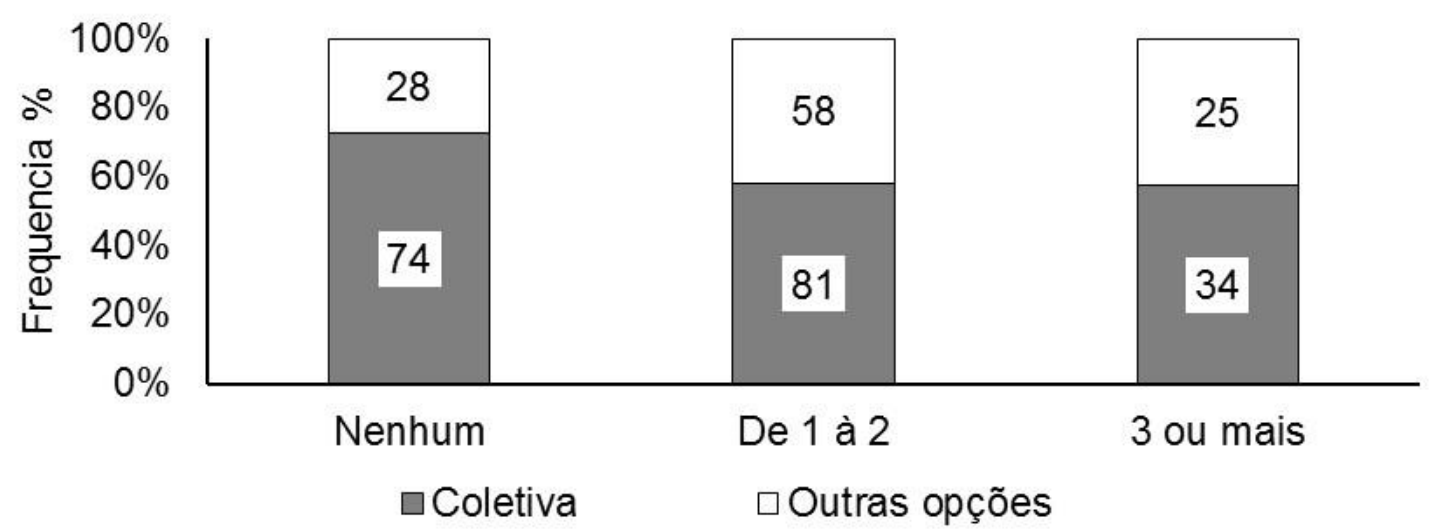

Figura 4: Frequências percentuais para a percepção da responsabilidade pela situação hídrica atual de acordo com o número de filhos, os valores apresentados nas barras referen-se às frequências absolutas.

O número de entrevistados que consideram a responsabilidade como coletiva decresce com a idade, porém não de forma significativa ( $X 2=5,0371$, $G L=4$ e $p>0,05$ ), sugerindo que os respondentes mais jovens manifestem uma percepção mais abrangente da questão, não obstante as diferenças no número amostral em cada categoria. O domínio da informação é um importante fator para a solução das questões ambientais, González-Gaudiano e MaldonadoGonzález (2014) perceberam maior conhecimento sobre as mudanças climáticas globais em indivíduos mais jovens, embora isso não se traduzisse em atitudes efetivas para o enfrentamento da questão (Figura 5).

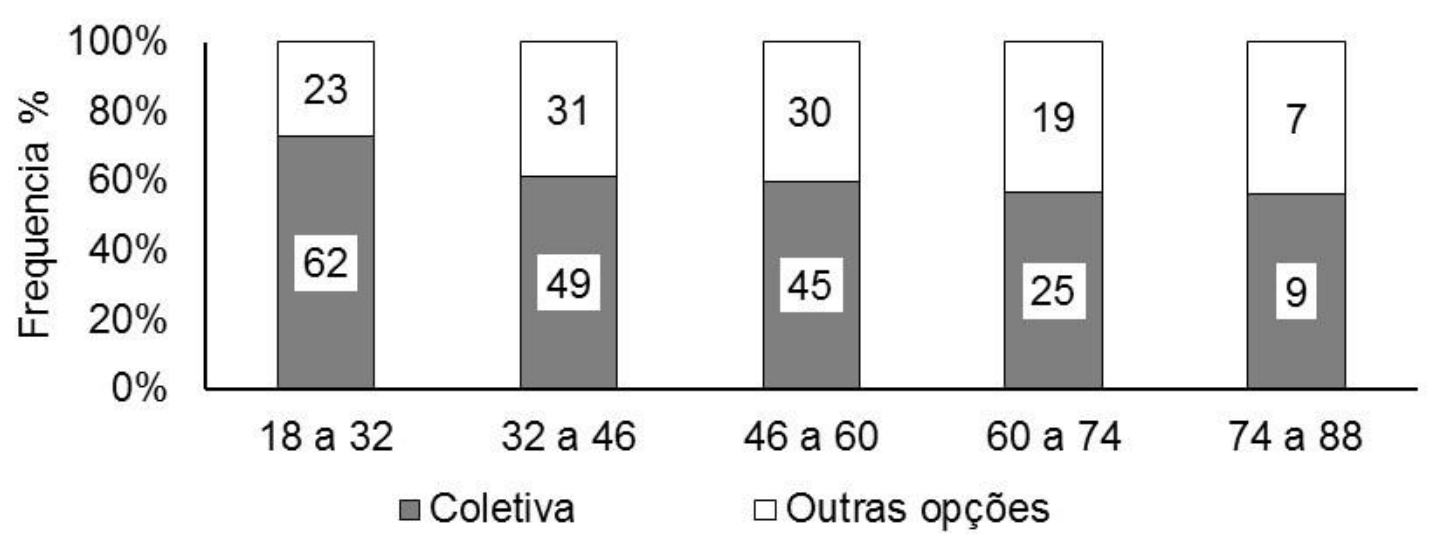

Figura 5: Frequências percentuais para a percepção da responsabilidade pela situação hídrica atual de acordo com a idade, os valores apresentados nas barras referen-se às frequências absolutas. 


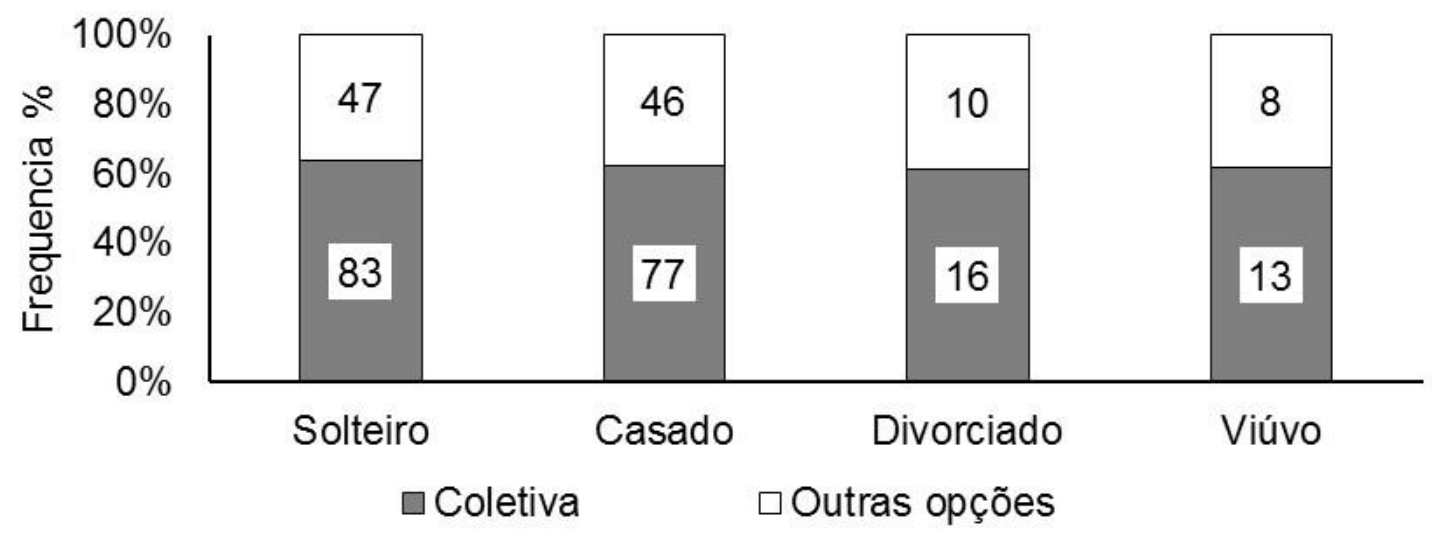

Figura 6: Frequências percentuais para a percepção da responsabilidade pela situação hídrica atual de acordo com o estado civil, os valores apresentados nas barras referen-se às frequências absolutas.

Tanto os respondentes que residem em casas, como os que residem em apartamentos, apresentam resultados semelhantes, com a maioria assinalando a responsabilidade como coletiva, porém sem diferenças significativas $(X 2=0,2084, \quad G L=1$ e $p>0,05)$ entre as proporções correspondentes aos tipos de moradia (Figura 7).

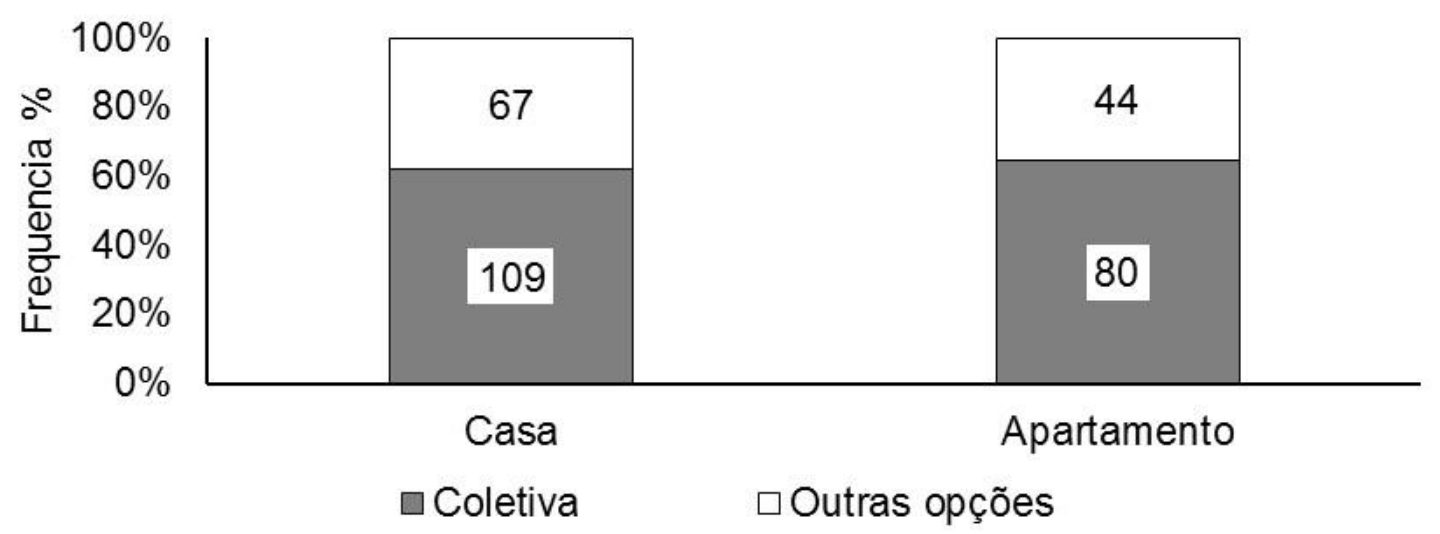

Figura 7: Frequências percentuais para a percepção da responsabilidade pela situação hídrica atual de acordo com o tipo de moradia, os valores apresentados nas barras referen-se às frequências absolutas.

O maior nível de escolaridade está significativamente $(X 2=11,2874$, $G L=2$ e $p<0,05)$ relacionado às maiores frequências de respondentes que assinalaram a opção referente à responsabilidade coletiva. Pesquisando sobre a percepção das mudanças climáticas globais, no México, González-Gaudiano e Maldonado-González (2014), obtiveram resultados semelhantes, porém, não registraram que atitudes cotidianas referentes ao enfrentamento da questão estejam relacionadas à maior escolaridade (Figura 8). Cabe lembrar que 0 acesso à informação também deveria ocorrer através das diversas mídias 
disponíveis ao cidadão, embora os estudos de Cimadevilla (2005), Martins Fernandes (2001) e Moreira Jr et a.l, 2015, destaquem que garantir a audiência seja a meta a prioritária comum à todas empresas de comunicação, o que faz com que a temática ambiental seja abordada de forma circunstancial, simplista e/ou sensacionalista e sempre de forma superficial, descontinuada e desintegrada da realidade do cidadão.

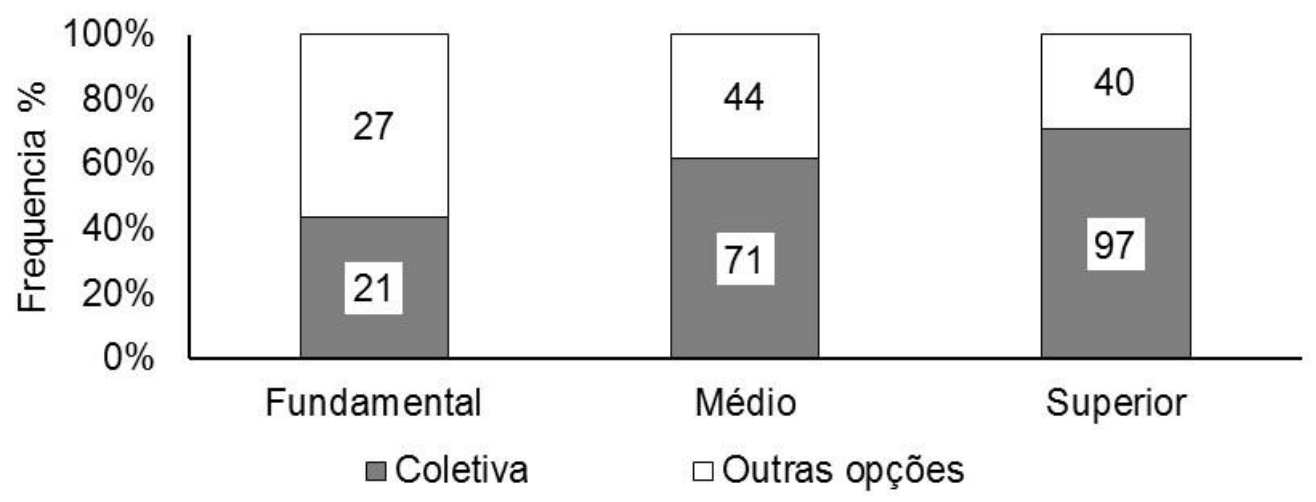

Figura 8: Frequências percentuais para a percepção da responsabilidade pela situação hídrica atual de acordo com a escolaridade, os valores apresentados nas barras referen-se às frequências absolutas.

A frequência de resposta que considerem a responsabilidade como coletiva é progressivamente superior à partir da categoria correspondente aos que recebem de 1 a 3 salários mínimos, porém não de forma significativa $(X 2=5,5978, G L=4$ e $p>0,05)$. Este resultado demonstra que o aumento da renda pode contribuir para a melhoria da percepção do cidadão, por possibilitar maior nível de escolaridade e acesso à informação. Não obstante, Dias (2014) sugere que disparidades econômicas entre diferentes regiões estejam relacionadas aos impactos ambientais negativos e que, uma sociedade justa, equitativa, democrática e igualitária seja um pre-requisito para a sustentabilidade (Figura 9).

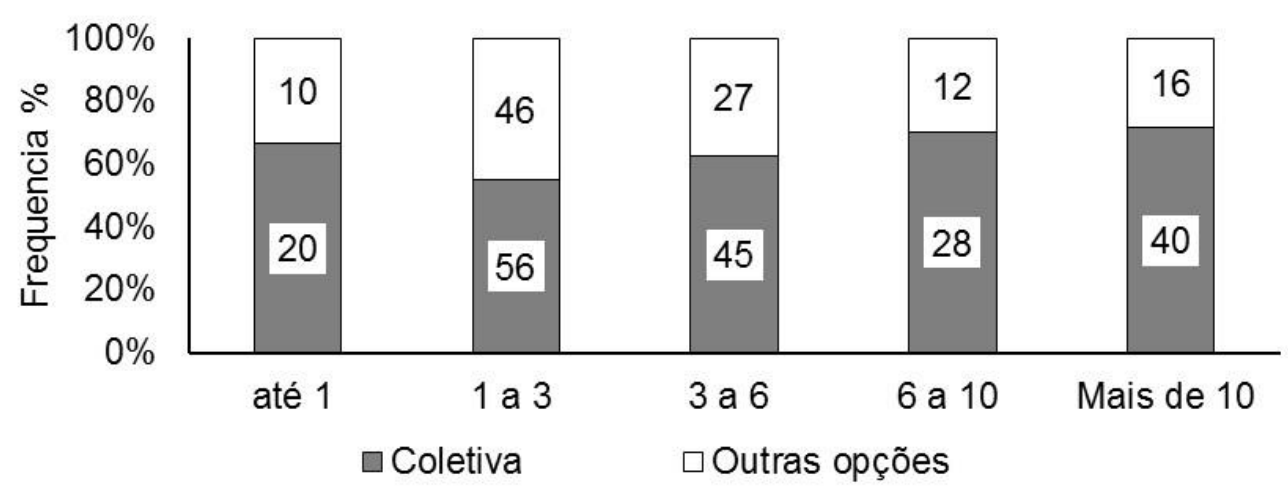

Figura 9: Frequências percentuais para a percepção da responsabilidade pela situação hídrica atual de acordo com a renda em salários mínimos, os valores apresentados nas barras referem-se às frequências absolutas. 
O regime de abastecimento diário foi quase unanimidade entre os respondentes, se percebendo que não ocorreram diferenças significativas ( $\mathrm{X} 2=0,0038, G L=1$ e $p>0,05)$ entre as proporções referentes ao regime de abastecimento, se observando maior frequência de respondentes que assinalaram a responsabilidade como coletiva (Figura 10).

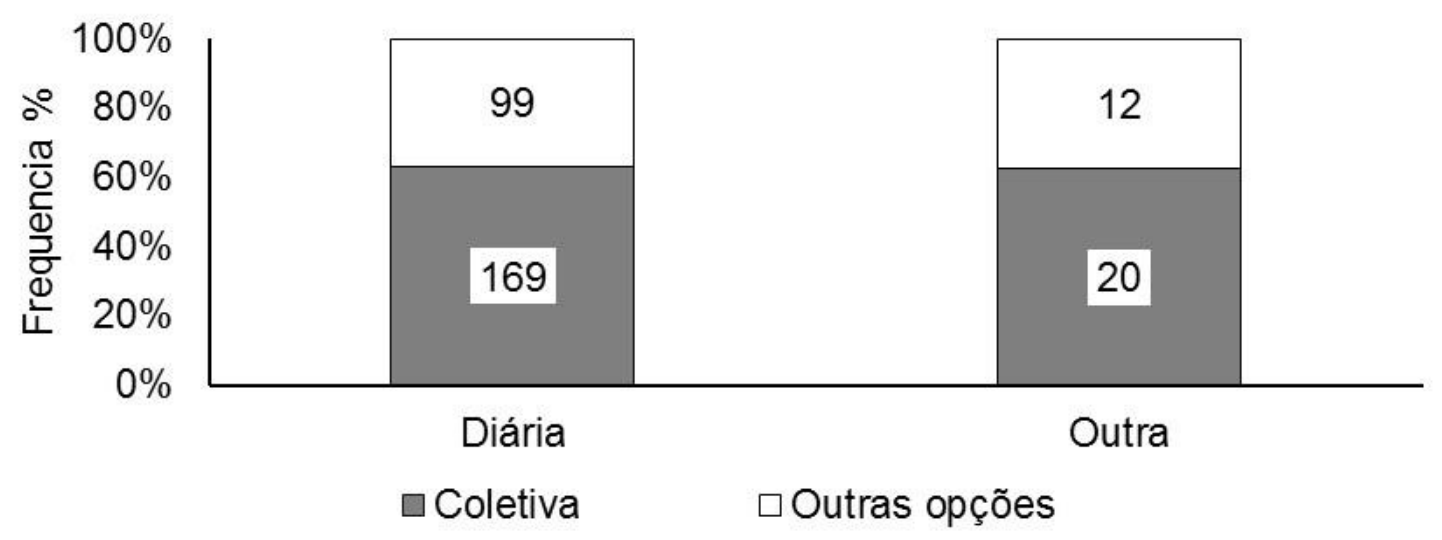

Figura 10: Frequências percentuais para a percepção da responsabilidade pela situação hídrica atual de acordo com a frequência de abastecimento pela rede de água, os valores apresentados nas barras referen-se às frequências absolutas.

A grande maioria dos respondentes afirmou dispor de hidrômetro em seus domicílios e se registraram padrões semelhantes aos já observados em relação a atribuição das responsabilidades pela situação hídrica, sem diferenças significativas $(X 2=0,0003, G L=1$ e $p>0,05)$ entre as proporções observadas para os que possuem ou não hidrômetro em seus domicílios (Figura 11).

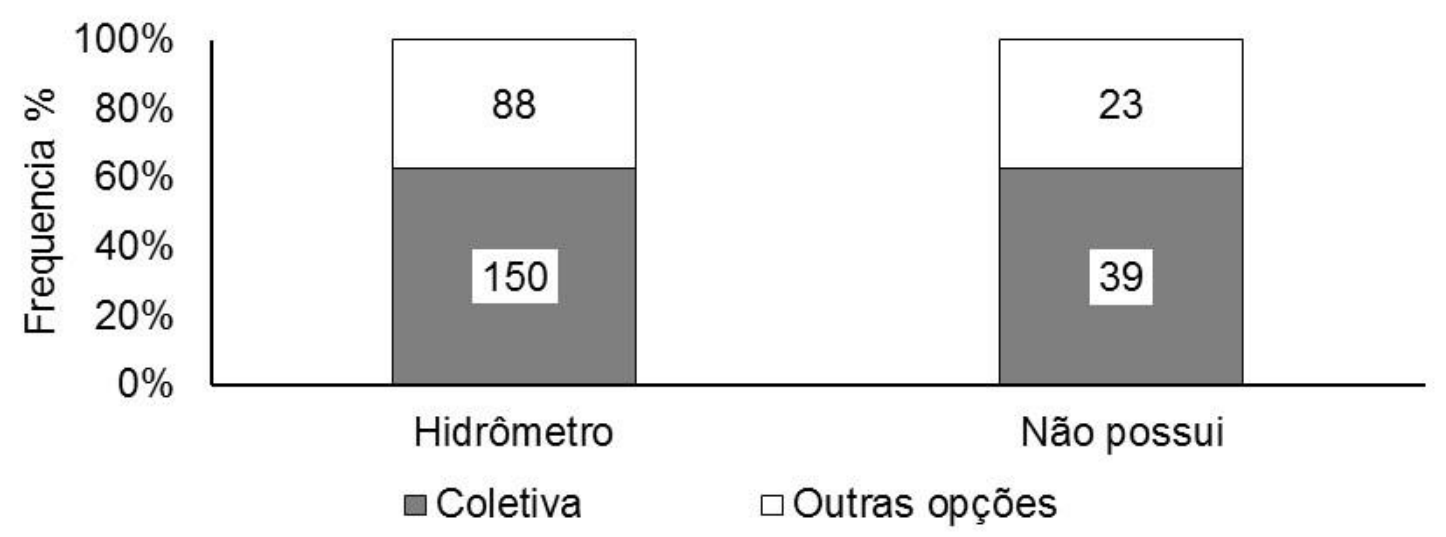

Figura 11: Frequências percentuais para a percepção da responsabilidade pela situação hídrica atual de acordo com a presença de hidrometro no domicílio, os valores apresentados nas barras referem-se às frequências absolutas. 


\section{Considerações finais}

A partir da análise dos resultados acima apresentados e discutidos, percebe-se que, algumas variáveis do perfil socioeconômico tiveram influência significativa, sugerindo-se aqui a seguinte ordem de importância: bairro, escolaridade, ocupação e número de filhos. Registrando-se, no geral, que a responsabilidade pela atual situação foi mais frequentemente (>50\%) atribuída a toda a coletividade, isso pode representar uma situação, ainda, crítica, pois Maria et al. (2008) afirmam ser necessário identificar e demonstrar as responsabilidades e o protagonismo aos indivíduos, por sua vez, Gumucio e Rau (2012) ressaltam que o governo e a academia têm responsabilidade e papel predominantes nesse cenário, pois com uso das mídias, podem disponibilizar a informação e, em decorrência, propiciarão a adoção de atitudes coerentes.

O maior conhecimento do grande público quanto a questões ambientais, observado nos países desenvolvidos (BERK; SCHULMAN, 1995), não se evidencia em países como o Brasil, onde são poucos os trabalhos dessa natureza e ainda se verificam confusões como as registradas por Barros e Pinheiro (2013), isso preocupa, pois, os estudos de Bispo e Oliveira, 2008 ressaltam a importância do conhecimento sobre as questões ambientais como o fator preponderante para as mudanças na percepção e atitudes.

Os trabalhos de Jacobi et al. (2011), no Brasil, e de GonzálezGaudiano e Maldonado-González (2014), no México, não evidenciam uma proficuidade de pesquisas sobre a responsabilidade dos atores sociais em relação às questões ambientais, não obstante a inegavel e enorme responsabilidade das autoridades instituidas, entre elas, destacamos aqui, a academia e as empresas de comunicação, que deveriam informar a população e assim, conjuntamente, tomar atitudes de enfrentamento da situação, como sugerem Tamaio (2013) e Dias (2014).

O presente estudo demonstrou que existe uma relação entre as variáveis do perfil socioeconômico e a percepção ambiental dos entrevistados. Fornecendo subsídios técnicos para ajustes e a criação de programas de educação ambiental que direcionem conteúdos e estratégias específicas a públicos alvos diferenciados. Os resultados aqui apresentados evidenciam que o desenvolvimento social influencia bastante no perfil dos respondentes e assim na sua percepção da situação, levando a crer que o investimento no desenvolvimento social deva ser priorizado estrategicamente visando soluções em longo prazo, pois entre as medidas essenciais para o enfrentamento da crise hídrica se destacam os estudos sobre a vulnerabilidade e resiliência das comunidades e dos ecossistemas, além do estudo, desenvolvimento e adoção de estratégias para a adaptação, porém, chama a atenção e preocupa a acomodação e a inércia da sociedade civil, como também registrou Fernandes et al (2004) ao perceber que os cidadãos são favoráveis à que se combata os problemas sócioambientais, porém, poucos desejam atuar nesse combate. 


\section{Referências}

BADEN, S. Practical Strategies for Involving Women as well as Men in Water and Sanitation Activities. SIDA, Brighton, IDS, BRIDGE, 1993.

BARROS, H.C.L.; PINHEIRO, J.Q. Dimensões psicológicas do aquecimento global conforme a visão de adolescentes brasileiros. Estudos de Psicologia, v. 18, n. 2, p. 173-182, 2013.

BERK, R.A.; SCHULMAN, D. Public perceptions of Global Warming. Climate Change, v. 29, p.1-33, 1995.

BISPO, M.O.; OLIVEIRA, S.F. Tecendo saberes, fazeres e práticas reflexivas a partir das representações de meio ambiente e educação ambiental de professores e estudantes. Anais do ENAMPPAS, 2, Indaiatuba-SP,2008.

CIMADEVILLA, G. Información ambiental, espectacularización y desconexión. Políticas de economía, ambiente y sociedad en tiempos de globalización, 2005, pp.111-130.

DIAS, G. F. Mudança Climática e você. São Paulo: Gaia, 2014, 267 p.

FERNANDES, R.S.; SOUZA, V.J.; PELISSARI, V.B.; FERNANDES, S.T. Uso da percepção ambiental como instrumento de gestão em aplicações ligadas às áreas educacional, social e ambiental. Anais do ENAMPPAS, 2, Indaiatuba-SP,2008.

GONZALEZ-GAUDIANO, E.; MALDONADO-GONZÁLEZ, A.L. Qué piensan, dicen y hacen los jóvenes universitários sobre el cambio climático? Un estúdio de representaciones sociales. Educar em Revista, Curitiba, ed. esp., n. 3, p. 35-55, 2014.

GUMUCIO, C.P.; RAU, J.M. Elites Universitarias y Cambio Climático. Ambiente e Educação, v.15, n.2, p. 195-2018, 2012.

IPP. Índice de Desenvolvimento Social - IDS: comparando as realidades microurbanas da cidade do Rio de Janeiro, Prefeitura da Cidade do Rio de Janeiro, Instituto Pereira Passos, 2008.

JACOBI, P.R.; GUERRA, A.F.S.; SULAIMAN, S.N.; NEPOMUCENO, T. Mudanças climáticas: a resposta da educação. Revista Brasileira de Educação, v.16, n.46, p.135-148, 2011.

LIMA, G.F.C.; LAYRARGUES, P.P. Mudanças climáticas, educação e meio ambiente. Educar em Revista, Curitiba, ed. esp., n. 3, p. 73-88, 2014.

MARIA, J.A.; CAVALCANTI, I.; EIRÓ, F.H. Percepção Ambiental e Mudanças Climáticas. Anais do Encontro da Sociedade Brasileira de Economia Ecológica, v.9, Brasília, 2011, 20 p.

MARTINS FERNANDES, A.F. O papel da mídia na defesa do meio ambiente. Revista de Ciências Humanas - UNITAU, Taubaté, SP 2001. 
MOREIRA JR, D.P.; BROTTO, D.S.; TUBINO, M.F.A. A rio+20 e a mídia impressa carioca: o espaço reservado às matérias temáticas. Revista Ciências Humanas - UNITAU, Taubaté/SP - Brasil, v. 8, n 2, edição 15, p. 81 - 91, Dezembro 2015

PEDRINI, A.G.; BROTTO, D.S.; LOPES, M.C.; FERREIRA, L.P. Percepções sobre meio ambiente e o mar por interessados em ecoturismo marinho na área de proteção ambiental marinha de Armação de Búzios, Estado do Rio de Janeiro, RJ, Brasil. Pesquisa em Educação Ambiental (Online), v. 8, 2013, p. 59-75.

TAMAIO, I. Educação Ambiental \& Mudanças Climáticas: diálogo necessário num mundo em transição. Brasília: DEA/MMA, 2013, 98 p

TUAN, Yi-Fu. Topofilia: um estudo de percepção, atitudes e valores do meio ambiente. São Paulo: Difel, 1980. 288p. 